\title{
Numerical study of the relationship between seismic wave parameters and remotely triggered rockburst damage in hard rock tunnels
}

\author{
MJ Raffaldi National Institute for Occupational Safety and Health, USA \\ DJA Chambers National Institute for Occupational Safety and Health, USA \\ JC Johnson University of Utah, USA
}

\begin{abstract}
Rockbursts are a serious hazard to workers in deep and high stress mines. Researchers with the National Institute for Occupational Safety and Health, Spokane Mining Research Division in Spokane, Washington, United States of America are using fully dynamic numerical modelling software to investigate rock fracture, ejection, and ground support demand in underground mine openings resulting from strong ground motion induced by a remote seismic source. In this study, a discrete element model of a typical metal mine drift supported by grouted rockbolts was subjected to seismic loading from a remote source. A parameter study was performed with respect to the ground motion by varying the peak particle velocity and frequency content of the input waveform. For each modelled seismic event, the resulting energy demand on the ground support is calculated. Other parameters - peak particle acceleration, duration, and radiated seismic energy - are considered implicitly. The results of this work provide insight into seismic loading of excavations and ground support and may partially explain why, in some cases, peak particle velocity does not correlate well with observed damage. Better understanding of the effects of seismic loading on excavations may lead to developments that improve the safety of workers in underground mines.
\end{abstract}

Keywords: dynamic modelling, rockburst, dynamic support, rock dynamics

\section{Introduction}

Rockbursting is a major challenge in mining ground control. Although not all rockbursts cause damage, and fortunately even fewer result in injury or fatality to underground workers, the economic and human consequences of a rockburst can be severe. There has been a considerable volume of rockburst research in recent decades. This work has focused primarily on dynamic mechanical and blast testing of ground support components and empirical observation of rockbursts and mining seismicity. Although this important work provides real world data, there have been few geomechanics based studies.

While mechanical tests are useful for determining relative energy capacities of ground support components, the loads applied in these tests are significantly different than those of real rockbursts. Further, the complex interactions between seismic waves, excavations, and ground support cannot be studied with these tests. Underground blast tests are conceptually more relatable to rockbursts, but the induced loads still differ significantly. Blast tests are also difficult to repeat and costly to perform. Empirical studies lend themselves to regression analyses of large databases that can yield great insight but are based solely on experience rather than the fundamental underlying mechanics. Until recently, fully dynamic discrete element modelling codes were not readily accessible and computing times required to run models with hundreds or thousands of discrete elements would have been unreasonable (even by research standards). This is no longer the case, and to advance understanding of rockbursting and dynamic ground support, fully-dynamic numerical modelling should play a larger role in research. 
The Spokane Mining Research Division of the National Institute for Occupation Safety and Health (Spokane, Washington, United States of America) has developed a rock mass modelling approach for simulating dynamic fracture and ejection of rock in response to interaction with seismic waves (Raffaldi \& Loken 2016a). This methodology was previously implemented in a two-dimensional (2D) model of a typical metal mine drift and used to perform a limited parameter study that investigated the relationship between seismic motion, rock ejection, and ground support demand for a remotely triggered rockburst event (Raffaldi \& Loken 2016b).

This paper presents the results of a larger parameter study that expands on this previous work to include a broader range of peak particle velocity (up to $5 \mathrm{~m} / \mathrm{s}$ ) and frequency $(20$ to $250 \mathrm{~Hz}$ ). Model results show that frequency is important to understanding seismic loading. Neither peak particle velocity (PPV) nor peak particle acceleration (PPA) provide a good correlation for ground support demand over a wide range of frequencies.

It is recognised that all geomechanical models, no matter how complex, are by necessity simplified mathematical descriptions of reality. The model presented in this paper is based on many simplifications and assumptions when compared to real mine geometry, rock properties, structure, condition, and complexity associated with seismic activity. However, simple models that capture mechanically significant features have often been valuable in data limited fields such as geomechanics (Starfield \& Cundall 1988). The objective of this study is not to perfectly simulate a remote seismic event and the subsequent damage resulting to an excavation. Rather, it is to use commercially available tools to develop a simplified model that can shed light on issues involving seismic damage to excavations and form a foundation for further research.

\section{Background}

Rockbursts may be classified as either 'self-initiated' when the seismic event and damage location coincide or 'remotely-triggered' when a seismic wave, propagated from a remote source, results in damage to an excavation (Kaiser et al. 1996). There are three fundamental categories of rockburst damage mechanisms (Kaiser et al. 1996): (1) rock bulking due to fracturing, (2) rock ejection due to seismic energy transfer, and (3) rockfalls induced by seismic shaking. The severity of rockburst damage can range from surface spalls and shallow slabbing to ejection of a metre or more of rock into an excavation (Kaiser et al. 1996). The work presented in this study is concerned only with remotely-triggered rockbursts resulting in dynamic ejection of rock.

The two most important factors influencing the severity of a rockburst - and, therefore, the demand on the ground support - are the magnitude of the event and the proximity of the event to the excavation (Potvin \& Wesseloo 2013), but the relationship between seismic loading, rock damage, and support demand is complex. In the absence of an exact solution, empirical ground support design practices have been proposed that relate ground conditions and some measure of the intensity of seismic loading, usually PPV, with support requirements (Wagner 1984; Kaiser et al. 1996; Potvin 2009). Empirical scaling laws have been developed that express the PPV of a seismic wave as a function of event magnitude and distance from the source (Hedley 1992; Butler \& Van Aswegen 1993; Kaiser \& Maloney 1997).

In mining, PPV has been found to offer several advantages over PPA (McGarr 1983): (1) for a given event magnitude, PPV falls within a much narrower range than PPA, (2) PPV better correlates with structural damage (McGarr et al. 1981), and (3) time histories of ground velocity can more accurately be modelled as a function of seismic event size. Dowding and Rosen (1978) found that a combination of both PPV and PPA best correlated with structural damage to underground tunnels caused by earthquakes. Dowding (1985) suggested that whether displacement, acceleration, or velocity is most appropriate for assessing potential for, and severity of damage depends on the frequency content of the stress wave. Kaiser and Maloney (1997, p. 419) have suggested that, "only low frequency accelerations, with wavelengths sufficiently long to accelerate the entire volume of rock in one direction, are relevant for damage prediction and support design."

Rock damage threshold values of PPV and PPA have been developed by various researchers for conventional blasts (Langefors \& Kihlstrom 1963; Bauer \& Calder 1970), nuclear detonations (Hendron 1977) and earthquakes (Dowding \& Rosen 1978; Sharma \& Judd 1991). In the rockbursting mines of the Witwatersrand region of South Africa it has been observed that generally, when PPV of a mining induced seismic event 
remains below about $1 \mathrm{~m} / \mathrm{s}$, little damage occurs (Wagner 1984). Blasting experiments in a South African mine have indicated that no visible damage is expected until PPV at a tunnel excavation exceeds $0.8 \mathrm{~m} / \mathrm{s}$ and that significant damage can be expected beyond $2 \mathrm{~m} / \mathrm{s}$ (Milev et al. 2001). An extensive monitoring program in stopes at eight South African mines showed that a reasonable assumption for maximum expected PPV from a mining induced seismic event would not greatly exceed $3.0 \mathrm{~m} / \mathrm{s}$ (Milev \& Spottiswoode 2005).

While PPV normally scales well with event magnitude and distance from the source, attempts to relate rockburst damage with PPV (usually estimated via scaling laws) often result in poor correlation (Potvin \& Wesseloo 2013). An analysis of 133 rockburst events at the Creighton Mine in Ontario, Canada, (Morissette et al. 2012) concluded that PPV, as estimated from the event magnitude and source distance, was not sufficient to predict damage (Figure 1). Cichowicz (1997) reported that an analysis of seismic and ground fall data at East Rand Proprietary Mine found estimated PPVs well below $1 \mathrm{~m} / \mathrm{s}$ could cause damage. More complex empirical studies that account for excavation dimensions, rock strength, and stress conditions (Potvin 2009) have achieved better results, but are still associated with considerable scatter of data.

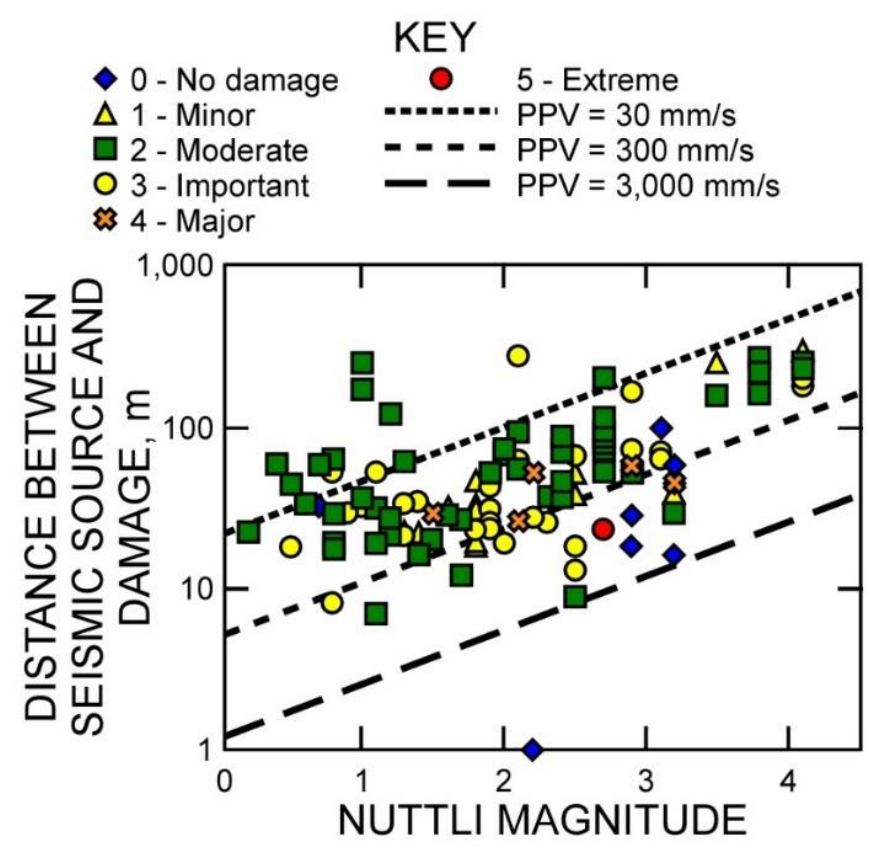

Figure 1 Magnitude-distance relation for rockbursts at the Creighton mine (after Morissette et al. 2012)

A limited understanding of reflection, refraction and attenuation of seismic waves in rock masses may explain a good deal of these results. In particular, the site effect, amplification of a seismic wave due to interaction with excavation geometry, geology, and the surrounding zone of fractured rock, may be of importance. It has been observed that PPV, at an excavation surface, can be amplified by as much as four to ten times that of the constrained wave (Cichowicz \& Durrheim 1997; Cichowicz et al. 2000; Durrheim et al. 1998; Milev et al. 1999; Milev \& Spottiswoode 2005). Milev \& Spottiswoode (2005) found that the measured site amplification was generally less for lower frequency ground motion. However, the site amplification was not found to correlate with estimated PPV or distance from the seismic source. The amplification of waves in the vicinity of an excavation has been observed to be highly variable, even within the same mine (Potvin \& Wesseloo 2013).

Researchers studying earthquakes and nuclear detonations (Labreche 1983; Hendron \& Fernandez 1983; Phillips \& Luke 1990; Lanzano et al. 2008) have stated that the ratio of the wavelength of the stress wave (or velocity wave) to excavation diameter $(\lambda / D)$ is an important factor for understanding the interaction of seismic waves with an excavation. In general, as $\lambda / D$ increases, loading approaches a quasi-static overpressure (Labreche 1983). Labreche suggests that seismic loading may be treated as quasi-static when $\lambda / D>5$. Phillips and Luke (1991) suggest that ground motion amplification of stresses is important when $\lambda / D<8$, while Lanzano et al. (2008) report that ground motion caused by earthquakes may be amplified if $\lambda / D$ is between one and four. 
Potvin and Wesseloo (2013) provide a more complete review of issues in mining seismicity and rockbursting that require further consideration in order to understand rockbursts and the demands they place on ground support. Use of numerical modelling may provide valuable insight into some of these problems and help clarify current understanding.

\section{$3 \quad$ Numerical model}

\subsection{Rock mass model}

A discrete element (DEM) rock mass model (Figure 2) was developed using the Universal Distinct Element Code (UDEC) version 6 (Itasca 2015). The basic approach has previously been used by Damjanac et al. (2007) for simulating earthquake damage to idealised emplacement drifts for an underground nuclear repository. The rock mass model has the capability to: (1) fail and deform in a ductile manner when under high confining stress, (2) fail and deform in a brittle manner when under low confining stress, (3) fracture and allow discrete rock blocks to detach from the intact rock mass under both static and dynamic loading conditions, and (4) transmit elastic waves with minimal distortion.

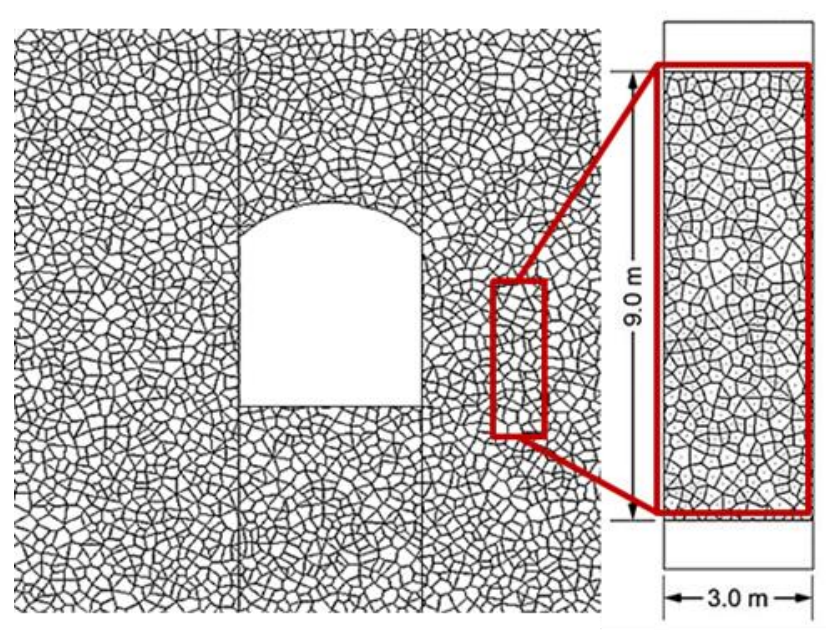

(a)

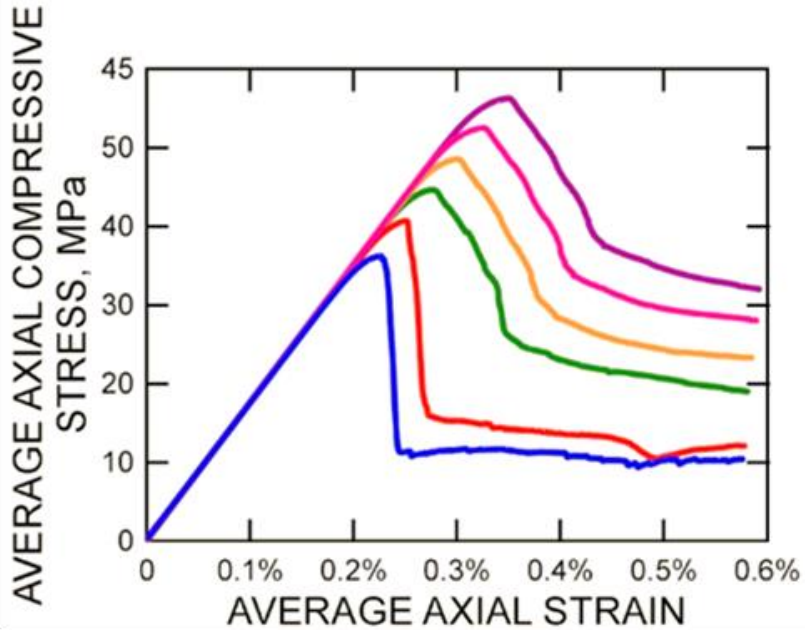

(b)

Figure 2 (a) Discrete element rock mass model; and, (b) numerical compression test results (at confining stress of 0 to $10 \mathrm{MPa}$ )

Before implementing the rock mass model into a 2D mine drift model, a series of tension and compression tests were simulated to validate the static response. The objective was to develop a rock mass model with an appropriate overall mechanical behaviour for a generic host rock, but that allows for internal fracture and detachment of blocks under appropriate stress conditions. The term 'validate' is used because the rock behaviour was not calibrated to any specific laboratory tests. Instead, properties were adjusted until modelled behaviour was considered reasonable. Figure 2 (b) shows the results from numerical compression tests. Tensile strength is about $0.3 \mathrm{MPa}$.

The fourth capability listed, minimal distortion of stress waves, was necessary because discontinuities in the model do not represent actual rock structure but exist solely to provide possible pathways for rock fracture. Therefore, it was important that no significant reflection or refraction of propagating stress waves occur at intact joints. A series of 1D numerical wave propagation experiments were performed to ensure adequate wave transmission in the model for the range of frequencies that would be simulated (up to $250 \mathrm{~Hz}$ ). Raffaldi and Loken (2016a) provide more detail on rock mass model development, input material properties and parameters, and static and dynamic validation. 


\subsection{Mine drift model}

The rock mass model discussed in Section 3.1 was incorporated into a 2D UDEC model of a $4 \mathrm{~m}$ wide, arched mine drift (Raffaldi \& Loken 2016b). The opening is located within a near-field region of discrete element blocks surrounded by a continuum far-field (Figure 3(a)). An initial equilibrium stress condition is applied to the model prior to excavation. After the drift is excavated, the model is again brought to static equilibrium. The excavation is then loaded dynamically by introducing seismic waves into the model from a 2D plate source located $25 \mathrm{~m}$ above the excavation. In the model, the rock surrounding the excavation is primarily intact prior to seismic loading, and fracture must first occur in order for rock to eject. In reality, a fractured zone may exist around excavations prior to dynamic loading. Depth of damage may be driven primarily by stress conditions rather than seismic loading. However, the modelled dynamic failure zone is not in situ stress independent. Raffaldi and Loken (2016b) showed that modelled ejection volume is significantly affected by in situ stress conditions.

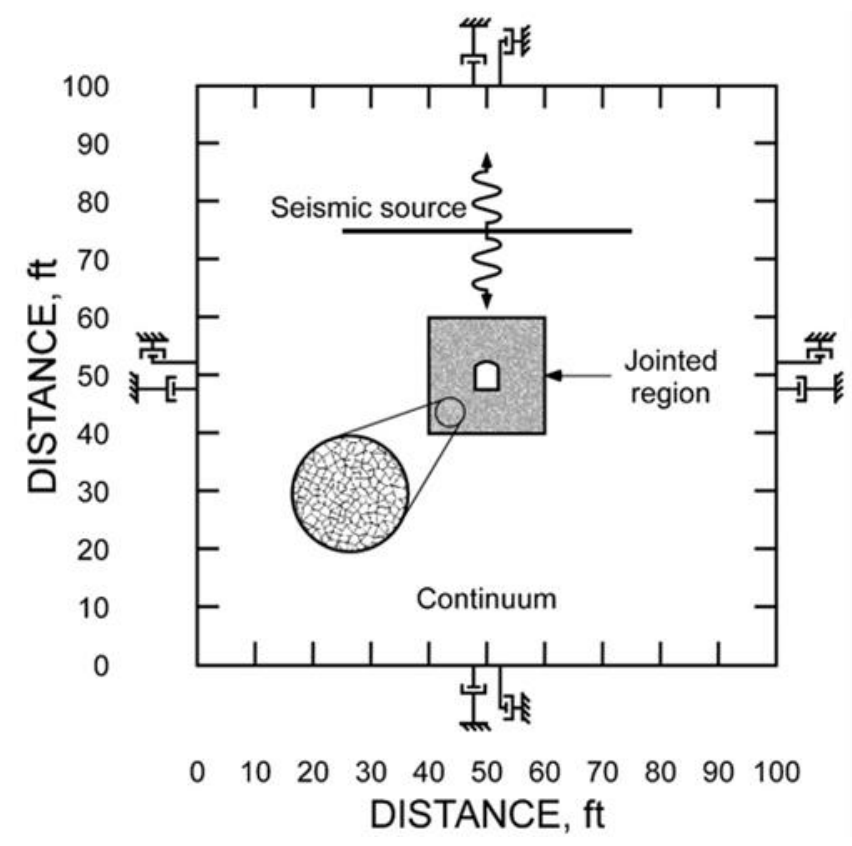

(a)

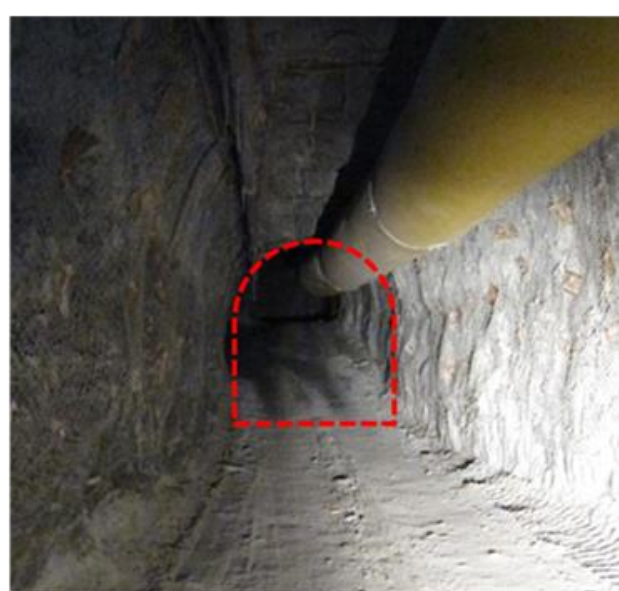

(b)

Figure 3 (a) Schematic of the dynamic UDEC model; and, (b) a typical arched development excavation

Energy absorbing viscous boundary conditions are applied along all external boundaries to prevent outgoing seismic waves from being reflected back into the model. Mechanical damping (attenuation) was not used in the model because the simulated wavelengths were quite large - the smallest wavelength being around $7 \mathrm{~m}$ (at $250 \mathrm{~Hz}$ ) - and because the different attenuation rates of higher and lower frequency components complicates parameter study results. Geometric spreading, resulting from an expanding wave front, causes some amplitude decay, but is limited by the size of the source relative to the drift (Figure 3(a)).

One problem with ignoring attenuation in a discontinuum model is that there is a potential for energy to become trapped in blocks. Although care was taken to ensure that joints were stiff, to minimise reflection and refraction of stress waves (Raffaldi \& Loken 2016a), the model is not homogenous or isotropic, and the joints can still potentially affect wave transmission. Ignoring damping greatly improves runtime (hours versus days) so for this study, such simplification was considered acceptable. It is also important to keep in mind that real seismicity is composed of many frequency components, and seismic events of larger magnitude tend to be associated with lower corner frequencies. Cichowicz (1997) provides an example of this phenomenon at a gold mine in South Africa. Additionally, the effects of higher frequencies is typically reduced with distance from the seismic source as a result of frequency-dependent attenuation. Higher frequencies are attenuated faster than lower frequencies. 
In the model, dynamic loading (as a shear velocity) is applied as a function of time. Either a synthetic waveform or a real waveform from measured ground motion may be used. In this work, synthetic waveforms were used of the form (Equation 1):

$$
v(t)=\frac{P P V}{2}\left[1-\cos \left(2 \pi f_{1} t\right)\right]\left[\sin \left(2 \pi f_{2} \mathrm{t}\right)\right]
$$

where:

$$
\begin{aligned}
& v(t)=\text { velocity as a function of time. } \\
& P P V=\text { peak particle velocity. } \\
& \mathrm{t}=\text { time. } \\
& f_{1}=\text { major frequency, defines the wave duration. } \\
& f_{2}=\text { minor frequency, defines the wave frequency content. }
\end{aligned}
$$

An example synthetic waveform is shown in Figure 4. The major frequency determines the duration of the dynamic loading, and the minor frequency defines the frequency content of the wave. The number of cycles contained in the wave is, therefore, a function of both $f_{1}$ and $f_{2}$. Peak particle velocity is determined by a constant, which scales the wave to the desired amplitude. Simplifying the input wave as a simple function with only a single frequency component facilitates parametric study.

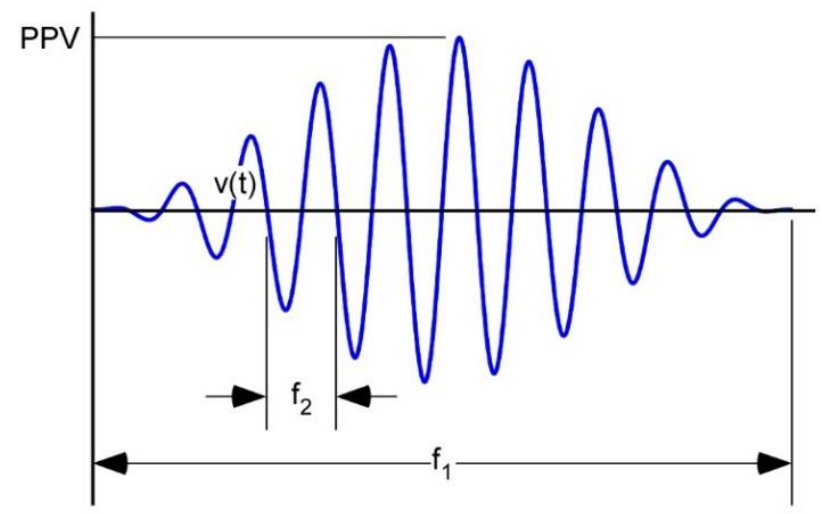

Figure 4 Synthetic waveform showing peak particle velocity, frequency, and event duration

It is important to remember that only the input seismic motion is specified, and this is not necessarily the motion at the excavation perimeter. For a number of reasons, such as amplification caused by reflection at a free surface, geometric spreading, resonance, and/or interaction with joints, the PPV at an excavation surface could be different than the input PPV. Such amplifications may develop in the model.

Support demand was estimated with new energy calculation features developed within the UDEC software for this work (Christianson 2015). These calculate and track rock ejection and the energy dissipated by the ground support elements. The ejection calculation detects the mass and velocity of blocks that have fully detached from the intact rock mass and then computes the total kinetic energy of these blocks. This is the energy that must be absorbed by a complete support system (containment, reinforcement, and connections) in order to contain ejected rock. The energy dissipated by the ground support considers both energy absorbed by yielding of the structural elements and energy dissipated by frictional sliding of reinforcement elements that shear through the grout. The sum total of dissipated energy is termed the ground support energy demand. Raffaldi and Loken (2016b) showed the modelled energy demand on the rockbolt elements is linearly proportional to the kinetic energy of ejected rock in corresponding unsupported models. 


\section{$4 \quad$ Model parameter study}

The initial parameter study reported by Raffaldi and Loken (2016b) was expanded to include a broader range of seismic loading parameters, bringing the total number of model runs to 61 . Frequencies between 20 and $250 \mathrm{~Hz}$ were considered. Mining seismicity may be associated with frequencies outside this range, but simulated frequencies were limited on the lower end of the spectrum by larger run times required for longer durations and, on the higher end of the spectrum, by model discretisation and block size. An analysis of seismic data from a South African mine reported corner frequencies ranging from roughly 10 to $100 \mathrm{~Hz}$ (Cichowicz 1997). In another study, corner frequencies as high as $350 \mathrm{~Hz}$ are reported (Cichowicz et al. 2000). PPVs as large as $5 \mathrm{~m} / \mathrm{s}$ were considered. Although $3.0 \mathrm{~m} / \mathrm{s}$ has been suggested as a practical upper limit of PPV (Milev \& Spottiswoode 2005), larger PPVs were required to cause significant damage in the model with frequencies below $40 \mathrm{~Hz}$.

PPA associated with these input motions was as low as $12 \cdot g$ and as high as $480 \cdot g$. The duration of the input waveforms ranged from 500 to $40 \mathrm{~ms}$. As mentioned, in order to keep the number of ground motion peaks constant for all simulated frequencies, it was necessary that lower frequencies have longer durations and vice versa. As a result, higher frequency input waveforms are associated with smaller $v^{2}$-integrals. The $v^{2}$-integral is computed as the time integral of the square of the velocity wave. If a spherical wavefront is assumed, the $\mathrm{v}^{2}$-integral (of a velocity waveform measured some distance from the source) can be used to compute the radiated seismic energy (Perret 1972), a measure of seismic source strength often used by seismologists.

Ground support consisted of $2 \mathrm{~m}$ long grouted rockbolts modelled with rockbolt structural elements available in UDEC. A total of 11 bolts were spaced roughly $1 \mathrm{~m}$ apart in the walls and back. The floor was left unsupported. Rockbolts were modelled as elastic perfectly-plastic with infinite elongation capacity. This prevented bolt rupture allowing total energy demand to be computed.

The total energy absorbed by the rockbolts was computed after each simulated seismic event. Table 1 summarises for each simulated frequency: the range of input PPV, number of model runs at that frequency, duration of motion, range of PPA associated with the input PPV range, range of $v^{2}$-integral, and range of resulting energy demand on the rockbolts.

Table 1 Summary of input seismic waveform parameters and resulting ground support energy demand

\begin{tabular}{ccccccc}
\hline $\begin{array}{c}\text { Frequency } \\
(\mathbf{H z})\end{array}$ & $\begin{array}{c}\text { PPV } \\
(\mathbf{m} / \mathbf{s})\end{array}$ & $\begin{array}{c}\text { Runs } \\
(\text { count) }\end{array}$ & $\begin{array}{c}\text { Duration } \\
(\mathbf{m s})\end{array}$ & $\begin{array}{c}\text { PPA } \\
(\mathbf{g})\end{array}$ & $\begin{array}{c}\mathbf{v}^{2} \text {-integral } \\
\left(\mathbf{m}^{2} / \mathbf{s}\right) \times 10^{3}\end{array}$ & $\begin{array}{c}\text { Energy } \\
\text { demand } \\
(\mathbf{k J})\end{array}$ \\
\hline 20 & $1.0-5.0$ & 9 & 500 & $12.8-64.0$ & $94-2,344$ & $0.0-10.6$ \\
\hline 25 & $1.0-4.5$ & 8 & 400 & $16.0-72.1$ & $75-1,519$ & $0.0-61.7$ \\
30 & $2.0-4.5$ & 6 & 333 & $38.4-86.5$ & $250-1,266$ & $0.0-254.4$ \\
\hline 40 & $1.0-4.0$ & 8 & 250 & $25.6-102.5$ & $47-750$ & $0.0-412.5$ \\
\hline 60 & $1.0-3.5$ & 7 & 167 & $38.4-134.5$ & $31-500$ & $0.9-336.9$ \\
\hline 100 & $1.0-3.0$ & 5 & 100 & $64.0-192.2$ & $19-169$ & $0.0-340.3$ \\
\hline 150 & $1.0-3.0$ & 6 & 67 & $96.1-288.2$ & $13-113$ & $0.7-313.5$ \\
\hline 200 & $1.0-3.0$ & 6 & 50 & $128.1-384.3$ & $9-84$ & $5.6-267.5$ \\
\hline 250 & $0.75-3.0$ & 6 & 40 & $120.1-480.4$ & $8-68$ & $0.4-205.7$ \\
\hline
\end{tabular}




\subsection{Peak particle velocity, peak particle acceleration, and support demand}

Model results were plotted as input waveform PPV or PPA versus support demand and grouped by frequency. Modelled energy demand versus the input wave PPV and PPA is shown in Figures 5(a) and 5(b), respectively. Open markers indicate rock damage that met or exceeded the bolt length $(2 \mathrm{~m})$.

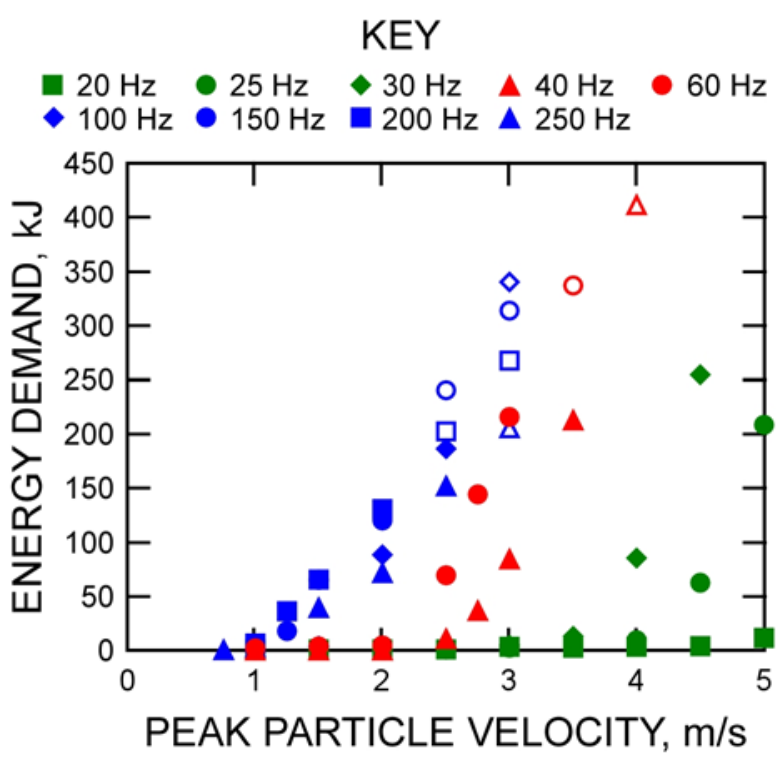

(a)

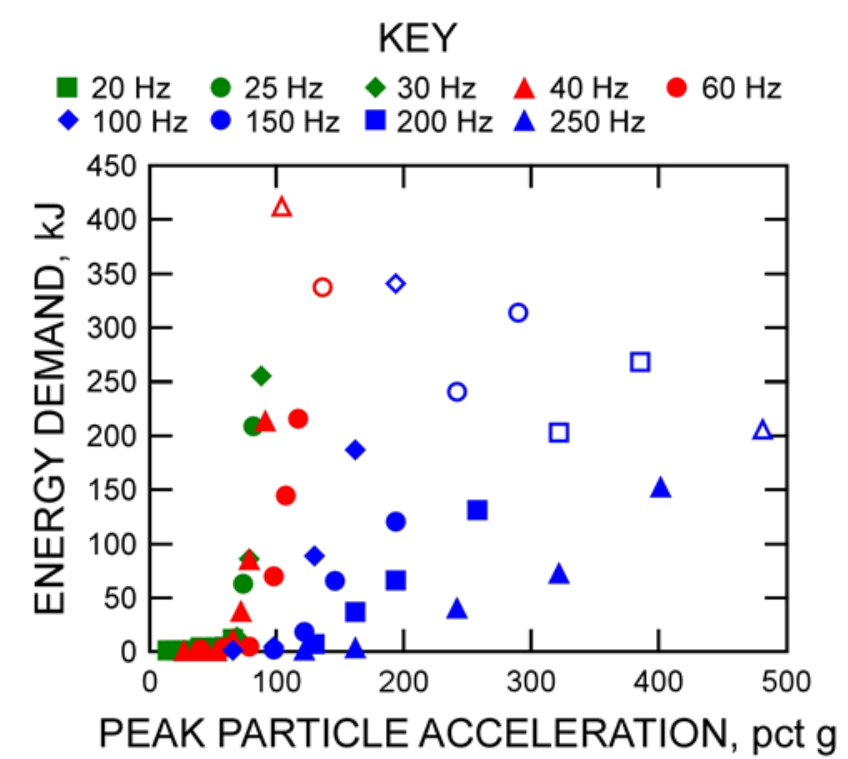

(b)

Figure 5 Modelled energy demand versus: (a) peak particle velocity; and, (b) peak particle acceleration of input wave for different simulated frequencies

It is observed that no energy is dissipated by the rockbolts until the input PPV exceeds about $1 \mathrm{~m} / \mathrm{s}$. Further increases in PPV result in increased support demand. Results are clearly frequency dependent, and only results from the highest frequency simulations $(100-250 \mathrm{~Hz})$ group together in a narrow band. PPV fails to provide a concise damage threshold for the full range of simulated frequencies. Neither does it correlate with modelled energy demand for all frequencies.

The acceleration damage threshold occurs around $65 . \mathrm{g}$, and like PPV, PPA does not fully explain the onset of damage or the modelled energy demand on the ground support for the full range of simulated frequencies. However, the results do group together in the $25-60 \mathrm{~Hz}$ range.

It is interesting to note that higher frequency loadings were associated with shorter total durations and much smaller $v^{2}$-integrals (measure of radiated seismic energy), as shown in Table 1. Despite this fact, high frequencies waves were still able to cause significant damage. Radiated seismic energy alone is not sufficient to determine how much energy is actually released through rock ejection.

Neither PPV nor PPA provides a good correlation with damage initiation or support demand for all simulated frequencies. For a real seismic event, the actual frequency content of the loading will consist of a range of frequency components that may be limited by the source mechanism and attenuation. It is well established that larger seismic moments are associated with smaller corner frequencies (Swanson et al. 2016).

\subsection{Frequency content and support demand}

From Figures 5(a) and 5(b) it is clear that frequency is an important factor for predicting the modelled damage threshold and energy demand. A plot of energy demand versus frequency is provided in Figure 6(a) with results grouped by input PPV. 


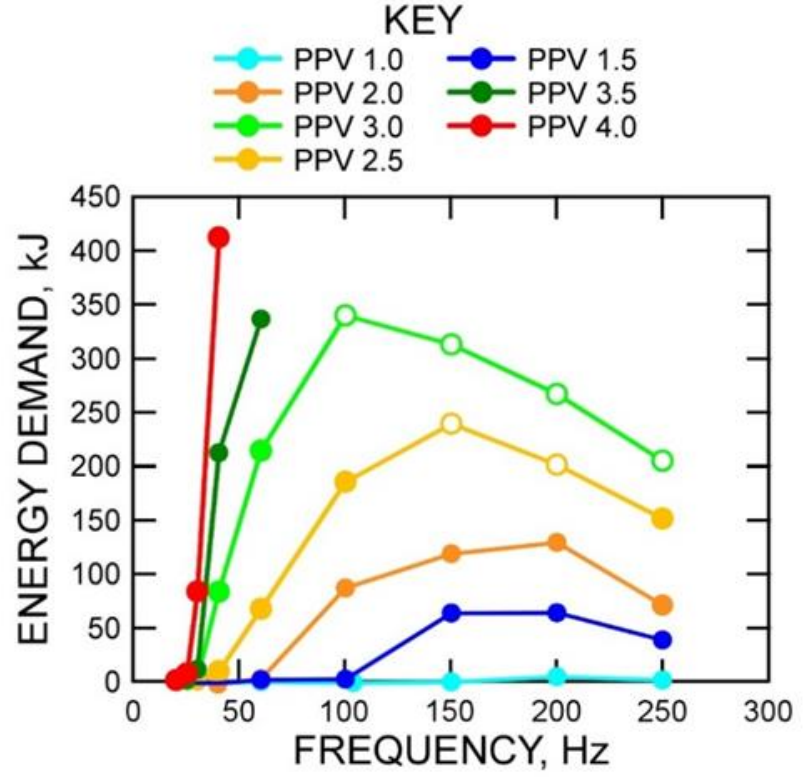

(a)

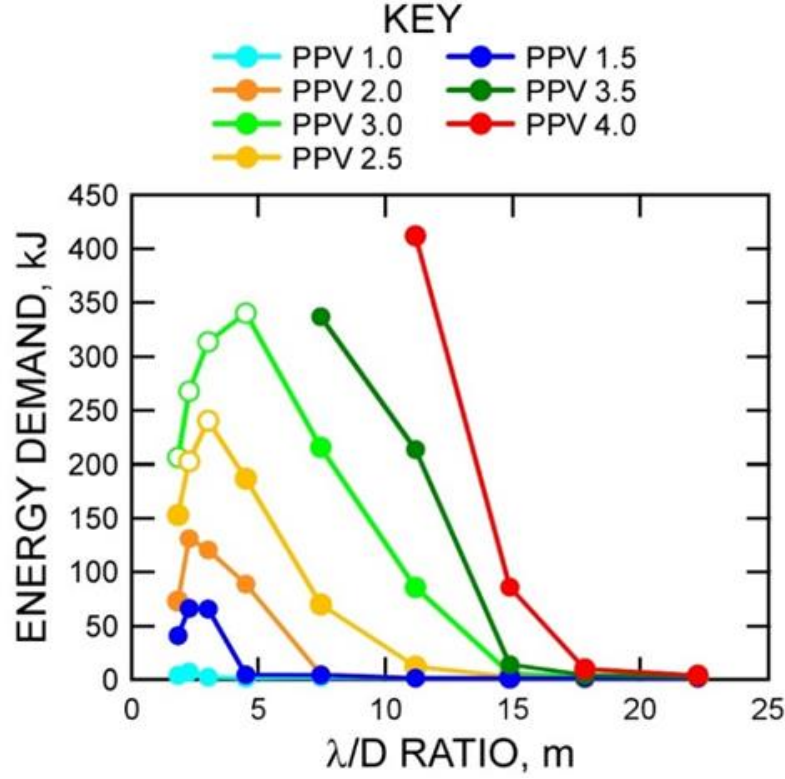

(b)

Figure 6 Ground support demand for a range of input waveform peak particle velocities versus: (a) input waveform frequency; and, (b) calculated wavelength-to-diameter $(\lambda / D)$ ratio

For each input PPV there is a frequency that is most damaging to the excavation. Additionally, waves with larger input PPV have a broader range of damaging frequencies. Again, for an actual seismic event, the frequency content of the stress wave will consist of a range of frequency components dependent on the source mechanism and attenuation.

The wavelength associated with each frequency was computed based on the shear wave speed through the discrete element rock mass of 1,780 m/s (Raffaldi \& Loken 2016a). Figure $6(\mathrm{~b})$ provides a graph of the modelled energy demand versus wavelength-to-excavation width for the same set of model data. A pronounced frequency effect is observed for a wavelength-to-width ratio $(\lambda / D)$ between two and six, with peaks well above those outside this range.

As previously mentioned, the PPV of the input motion is not necessarily the PPV that occurs at the surface of the excavation. In order to assess amplification in the model, a set of models were run with a non-damaging input PPV of $0.25 \mathrm{~m} / \mathrm{s}$. The resulting PPV normal to the centre span of the right and left walls was calculated and averaged for each frequency. The amplification factor, which is the ratio of the average PPV at the mid-span of the ribs to the input PPV, is plotted versus frequency in Figure 7.

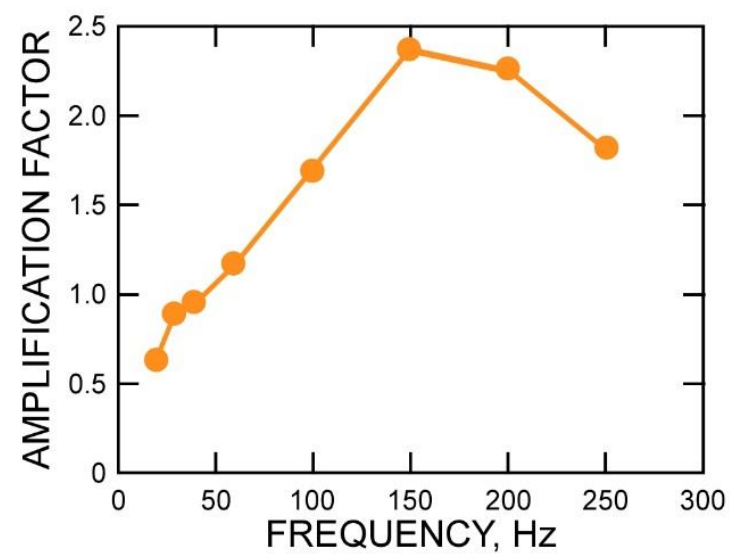

Figure 7 Velocity amplification factor (ratio of average velocity at excavation surface to input PPV) versus frequency for an input PPV of $0.25 \mathrm{~m} / \mathrm{s}$ 
The PPV amplification is significant, particularly for higher frequencies and has a maximum at $150 \mathrm{~Hz}$ $(\lambda / D=3)$. It is important to keep in mind, however, that Figure 7 is only a measure of the amplification at two points located at the centre spans of the excavation ribs, a location where maximum amplification could be expected. Amplification factors below 1.0 are probably a result of geometric spreading of the wave as it passes through the model.

\subsection{Rock fracture and ejection}

During the study, it was observed that for the same input PPV, waves of higher frequency were, in general, associated with larger fracture zones than waves of lower frequency. Although the PPV amplification discussed in Section 4.2 is likely an important factor, even when amplification is accounted for, PPV does not explain such observations. Two examples are shown in Figures 8 and 9.
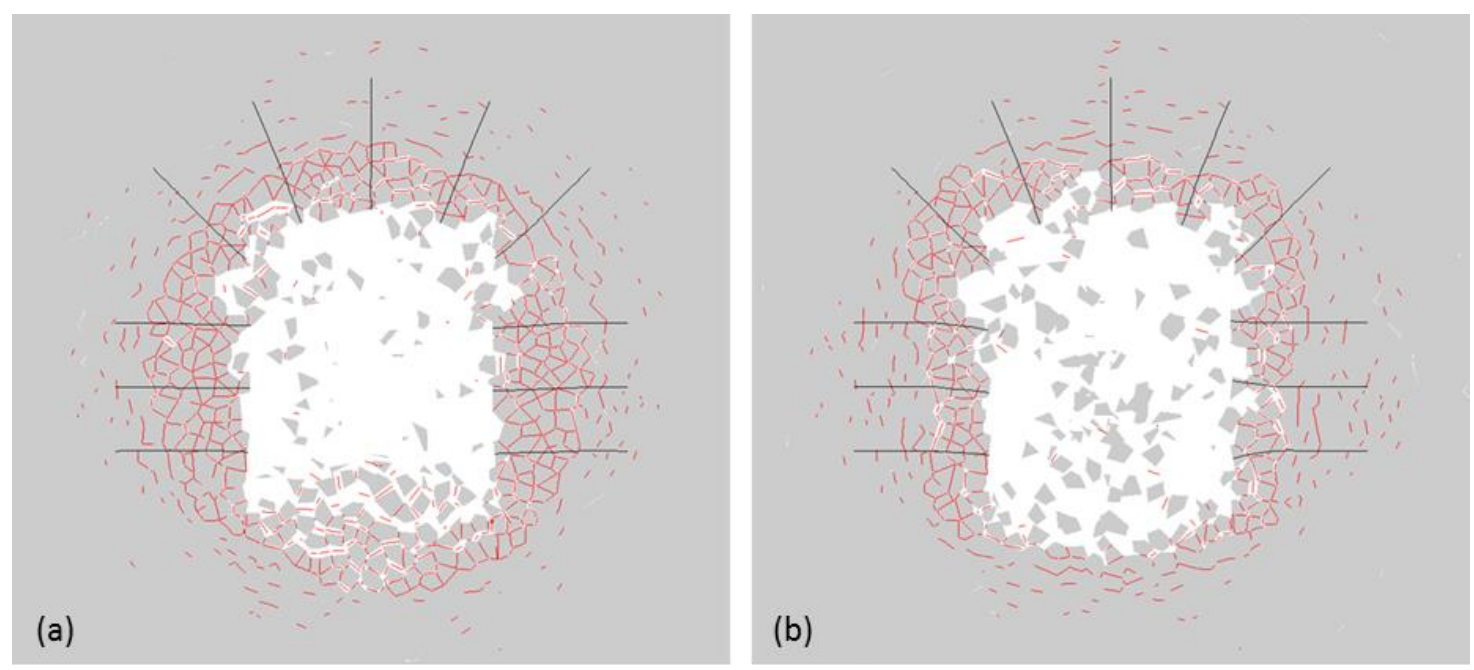

Figure 8 Modelled fracturing after simulated seismic loading of: (a) PPV of $2.5 \mathrm{~m} / \mathrm{s}$ and a frequency of $250 \mathrm{~Hz}$; and, (b) PPV of $4.5 \mathrm{~m} / \mathrm{s}$ and frequency of $30 \mathrm{~Hz}$
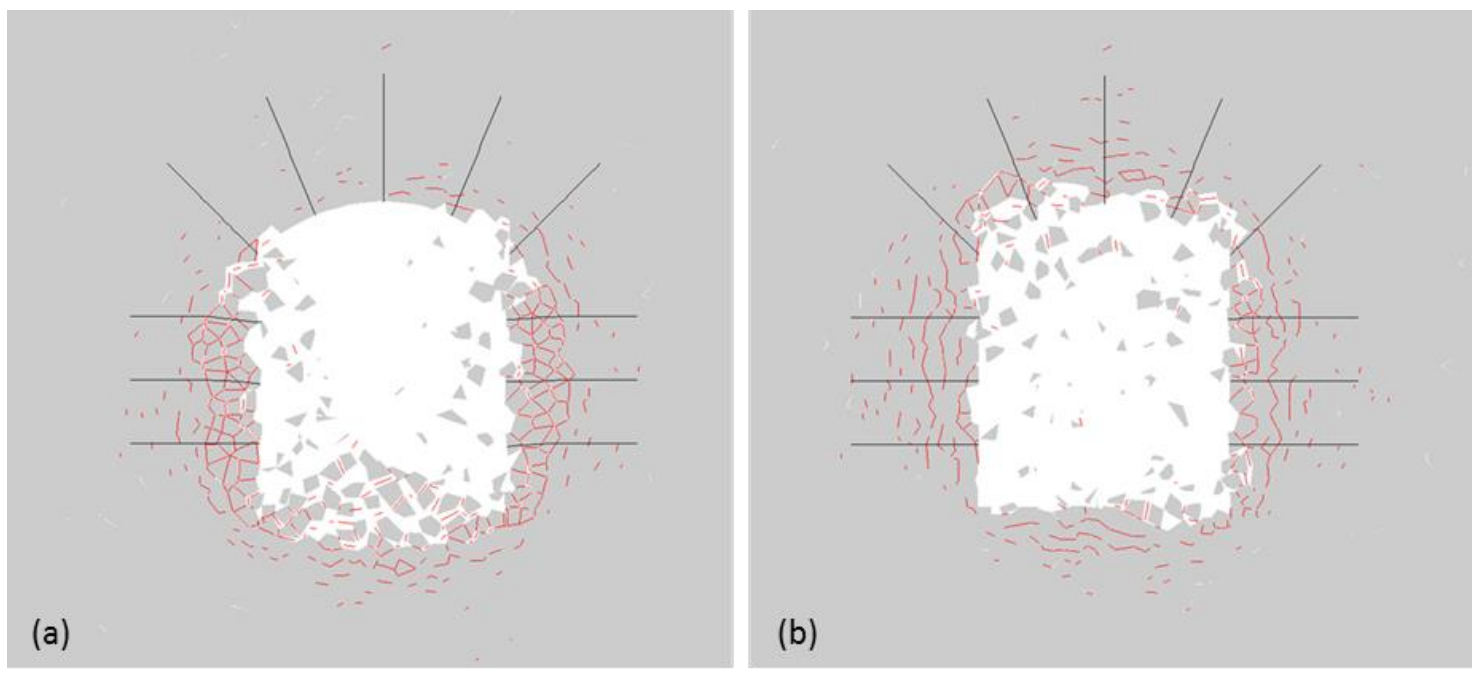

Figure 9 Modelled fracturing after simulated seismic loading of: (a) PPV of $2.0 \mathrm{~m} / \mathrm{s}$ and a frequency of $100 \mathrm{~Hz}$; and, (b) PPV of $4.0 \mathrm{~m} / \mathrm{s}$ and frequency of $30 \mathrm{~Hz}$

In Figure 8, the results of a simulation with seismic inputs of $2.5 \mathrm{~m} / \mathrm{s}$ and $250 \mathrm{~Hz}$ is compared with results from a simulation with seismic inputs of $4.5 \mathrm{~m} / \mathrm{s}$ and $30 \mathrm{~Hz}$. The $250 \mathrm{~Hz}$ input wave resulted in less energy demand on the support ( $152 \mathrm{~kJ}$ ) compared to the $30 \mathrm{~Hz}$ wave ( $254 \mathrm{~kJ}$ ) but (from visual inspection of Figure 8) fractured approximately the same volume of rock. If the velocity amplification factors from Figure 7 are assumed, the true PPV at the excavation surface for the $250 \mathrm{~Hz}$ wave was about $4.5 \mathrm{~m} / \mathrm{s}$, and the true PPV 
for the $30 \mathrm{~Hz}$ wave was roughly $4.0 \mathrm{~m} / \mathrm{s}$. This seems to clarify the discrepancy in rock damage but fails to reconcile the difference in energy demand. The $30 \mathrm{~Hz}$ wave resulted in slightly less fracturing of rock, had a lower (estimated) PPV, yet the energy demand on the support due to the $30 \mathrm{~Hz}$ wave was $65 \%$ more than that caused by the $250 \mathrm{~Hz}$ wave.

Figure 9 compares the fracturing that occurred in two simulations (PPV 2.0 at $100 \mathrm{~Hz}$; PPV $4.0 \mathrm{at} 30 \mathrm{~Hz}$ ) that resulted in the same total energy demand on the ground support. More fracturing was caused by the $100 \mathrm{~Hz}$ wave. If PPV for these cases is adjusted for amplification using Figure 7, the respective PPVs at the excavation surface for the 100 and $30 \mathrm{~Hz}$ waves are 3.4 and $3.5 \mathrm{~m} / \mathrm{s}$ (roughly the same), and although the two waves resulted in nearly the same energy demand (within $3 \%$ ), the $100 \mathrm{~Hz}$ wave caused more damage to the rock.

\section{Comparison with one-dimensional modelling results}

In addition to PPV amplification, frequency dependence may occur in another way. Raffaldi and Loken (2016a) used UDEC to simulate the 1D problem of ejection of a block bonded to the free surface of an infinite rod subjected to P-wave pulses with wavelengths much longer than the block dimensions (Figure 10). The results of this study are provided in Figures $11(\mathrm{a})$ and $11(\mathrm{~b})$ that show the velocity and acceleration of the block, at the time of joint failure, versus joint tensile strength for a range of input PPV and frequency. The results show that: (1) the fracture of the joint can be predicted by block acceleration, (2) for pulses of equal PPV the maximum joint strength that can be broken increases with increasing frequency, and (3) for pulses of equal PPV, the ejection velocity increases with frequency if joint strength is held constant.

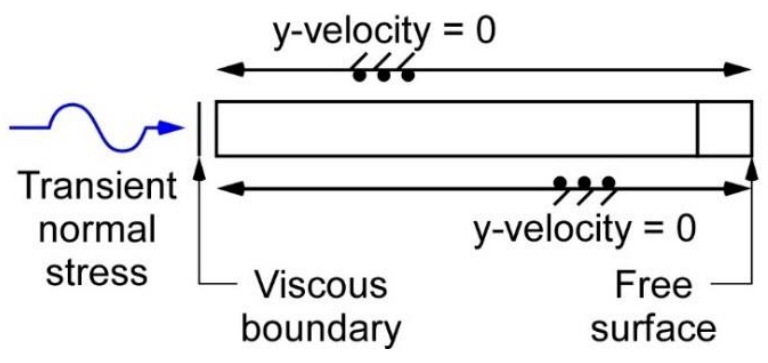

Figure 10 One-dimensional wave propagation model for investigating ejection of a single block

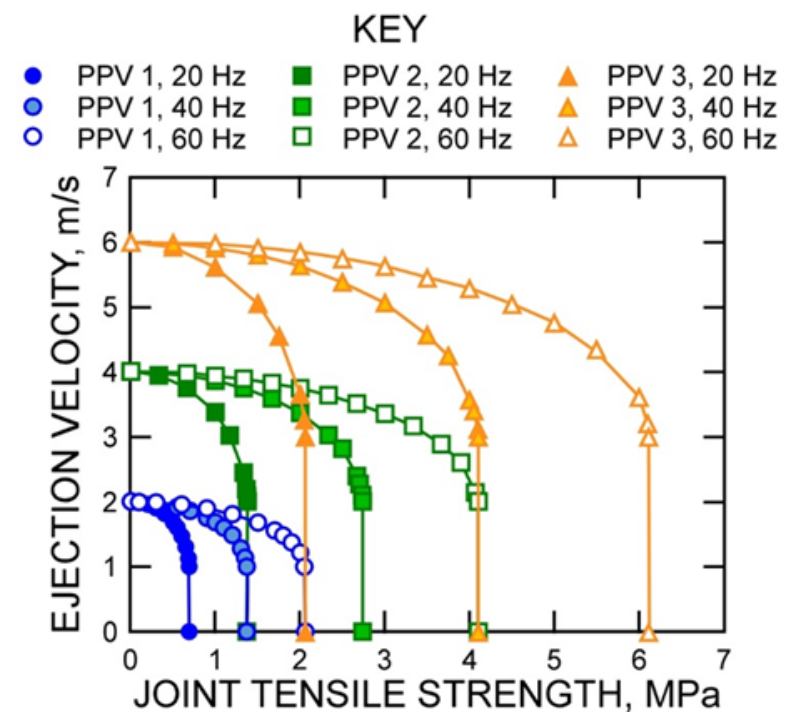

(a)

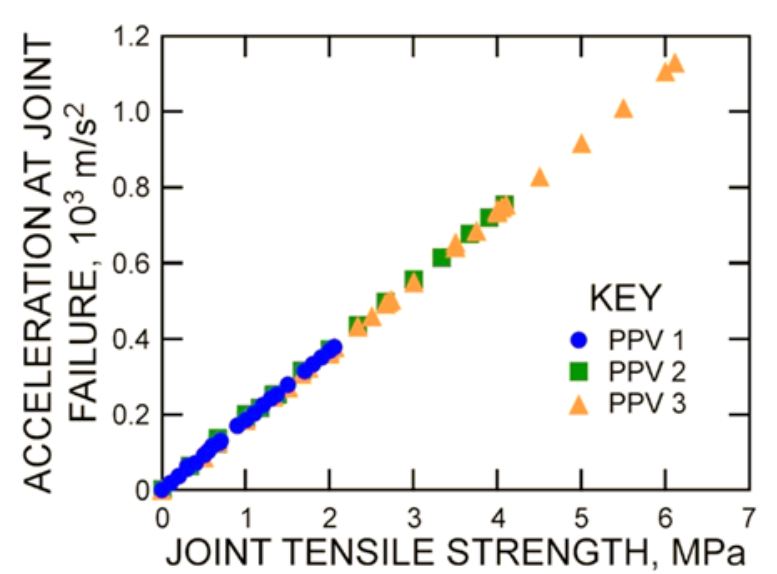

(b)

Figure 11 Relationship between: (a) ejection velocity; and, (b) acceleration at failure versus joint tensile strength

In the 2D excavation model, for simulated frequencies below $100 \mathrm{~Hz}$, considering Figures $5(\mathrm{a})$ and $5(\mathrm{~b})$, three analogous statements can be made: (1) PPA well describes the onset of damage, (2) the PPV damage 
threshold decreases with increasing frequency, and (3) for the same PPV, higher frequencies result in greater energy demand. No such analogy can be made for frequencies above $100 \mathrm{~Hz}$.

It should be pointed out that the 1D model results shown in Figure 11 are based on a predetermined failure location. The location of maximum dynamic stress with respect to the free surface depends on the frequency of the simulated wave. As the frequency decreases (and, likewise, the wavelength increases), the location of maximum dynamic stress occurs further away from the free surface, and, likewise, the maximum stress induced at the location of the joint decreases. However, although the location of maximum dynamic stress is frequency dependent, the magnitude, which is a function of PPV, is not. This can be visualised using methods described by Pariseau (2011). In the 1D model, one can imagine that as frequency becomes very high and the wavelengths become small with respect to the block size, although the tensile reflection may fracture the joint, ejection will not occur because the entire block is not mobilised in a single direction.

Such effects seem to appear in the 2D excavation model. Considering Figure 5(a), it is observed that at frequencies greater than $100 \mathrm{~Hz}$, the PPV damage threshold is effectively constant. However, considering the plot of support demand versus frequency (Figure 6(a)), it is observed that the energy demand decreases with increasing frequency beyond about $100 \mathrm{~Hz}$. Further, Figure 5 (b) shows that the relevance of acceleration (for assessing modelled support demand) decreases rapidly as frequency increases. For example, very large accelerations, even in excess of 100.g did not cause damage if the frequency of the seismic loading was in excess of $200 \mathrm{~Hz}$. This helps explain the statement by Kaiser and Maloney (1997) that accelerations are only relevant for low frequency loading in which the wavelengths are long enough to accelerate large volumes of rock in a single direction.

It is likely that the modelled frequency dependence of energy demand is a result of both PPV amplification and the boundary condition stress effects discussed in this section. To place an energy demand on the ground support, rock must be both fractured and ejected. Maximum ground support energy demand likely occurs at frequencies where the combination of damaged volume of rock mass and average ejection velocity of this mass results in maximum kinetic energy.

\section{Conclusion}

This work demonstrates the potential for dynamic discrete element modelling to aid in understanding complex phenomena associated with seismic loading of excavations and rock support. The developed model is idealised, but within its inherent limitations the following conclusions can be made from this study:

- Neither PPV nor PPA correlates with support demand over a wide range of simulated frequencies. However, if the frequency content does not vary between events, than either parameter would provide a good correlation with support demand.

- Whether PPV or PPA is the most appropriate measure of damage depends on the frequency content of the stress wave.

- For waves of equal PPV, frequency and acceleration are not independent variables. Therefore, predicting modelled damage is effectively a function of PPV and frequency. The number of incursions into a PPV damage threshold also plays a role but was not a variable in this study.

- Frequency content of the seismic wave appears to play a role in the depth of rock damage and the ejection velocity of the failed rock.

- Amplifications of particle velocity do occur in the model. Greater amplification occurs at frequencies of $100 \mathrm{~Hz}$ and above.

- Prediction of damage and support demand is complex and no single seismic wave parameter can account for all of the variations in the results.

The fact that PPV and PPA provided such a poor correlation with support demand in a simplified model highlights the difficulty in representing complex time dependent motion with a time independent parameter. 
Using synthetic waveforms defined by a single frequency is useful for parametric study, but frequency content of real mining induced seismicity may not vary so drastically between events of similar magnitude. Parameter study using waveforms recorded from real seismic activity in underground mines may provide more insight.

Empirical observations have suggested that PPV amplification generally increases with frequency. This was observed in the model. Maximum amplifications and support demand occurred within a range of wavelength-to-diameter that might be expected based on literature. The relationship between frequency (wavelength) and excavation dimensions could be further explored by varying excavation size and shape. Discrete element modelling may also provide a means of studying the effect of a fractured zone surrounding an excavation.

The current method of introducing seismic waves into the model has the advantage that it allows motion to be input explicitly but is fundamentally unrealistic. Incorporating an internal fault that generates seismic waves from an induced fault-slip event would provide a more realistic radiation pattern and also allow for parametric study of the source mechanism.

Though initial modelling results, in some respects, compare with empirical observation, whether or not the modelled mechanisms are correct is not yet known. The total number of input variables required for this simulation was in excess of 50 (Raffaldi \& Loken 2016b). This alone highlights the complexity of the problem. Only two of these variables were changed in the study (frequency and PPV). The effect of material properties, particularly the discontinuity properties and block size, on modelled outcomes are significant numerical considerations that require attention in order to effectively interpret model results.

Modelling research and development is needed to advance dynamic modelling codes to allow users to construct models with the complexity required to simulate dynamic source mechanisms, wave propagation, rock damage and fracture, local site conditions, and ground support. Improvements to, and innovative applications of, modelling software have the potential to illuminate complex and currently poorly understood issues in mining seismicity, rockbursting and dynamic support. Ultimately, comparison with empirical work (which is inherently grounded in reality) is required to determine the practical value of any modelling insights.

\section{Acknowledgement}

The authors thank Mark Christianson of Itasca Consulting Group, Inc. for assistance with using structural elements in UDEC, developing the energy calculations used in this work, and implementing these calculations into UDEC. Technical insight provided by Jeff Whyatt (University of Utah), Mark Board (Hecla Mining Company) and Marc Loken have also greatly contributed to this research.

\section{Disclaimer}

The findings and conclusions in this paper are those of the author(s) and do not necessarily represent the views of the National Institute for Occupational Safety and Health (NIOSH). Mention of any company or product does not constitute endorsement by NIOSH.

\section{References}

Bauer, A \& Calder, PN 1970, 'The influence and evaluation of blasting on stability', in CO Brawner \& V Milligan (eds), Proceedings of the 1st International Conference on Stability in Open Pit Mining, American Institute of Mining, Metallurgical, and Petroleum Engineers, New York, pp. 83-94.

Butler, AG \& Van Aswegen, G 1993, 'Ground velocity relationship based on a large sample of underground measurements in two South African mining operations', in RP Young, RP (ed.), Proceedings of the Third International Symposium on Rockbursts and Seismicity in Mines, CRC Press, pp. 41-51.

Christianson, M 2015, Energy Calculation Modifications in UDEC 6.0, report no. 2-1607-01, prepared by Itasca Consulting Group, for NIOSH Spokane Research Center, Spokane.

Cichowicz, A 1997, Development of A More Reliable Means of Assessing Safety Risk due to Rockbursts and Rockfalls as A Managerial Decision Support Technique, SIMRAC Final Project Report, Safety in Mines Research Advisory Committee, Johannesburg, pp. 1-46. 
Cichowicz, A \& Durrheim, RG 1997, 'The site response of the tunnel sidewall in a deep gold mine, analysis in the time domain', in Gurtunca, RG \& Hagan, TO (eds), Proceedings of the First Southern African Rock Engineering Symposium, pp. 56-61.

Cichowicz A, Milev, AM \& Durrheim, RJ 2000, 'Rock mass behaviour under seismic loading in a deep mine environment: implications for stope support', Journal of the Southern African Institute of Mining and Metallurgy, vol. 100, no. 2, pp. 121-128.

Damjanac, B, Board, M, Lin, M, Kicker, D \& Leem, J 2007, 'Mechanical degradation of emplacement drifts at Yucca Mountain - A modeling case study Part II: Lithophysal rock', International Journal of Rock Mechanics and Mining Sciences, vol. 44, pp. 368-399.

Dowding, CH 1985, Blast Vibration Monitoring and Control, Library of Congress, USA.

Dowding, CH \& Rosen, A 1978, 'Damage to rock tunnels from earthquake shaking,' Journal of the Geotechnical Engineering Division of the American Society of Civil Engineers, vol. 104, pp. 175-191.

Durrheim RJ, Roberts, MKC, Haile, AT, Hagan, TO, Jager, AG, Handley, MF, Spottiswoode, SM \& Ortlepp, WD 1998, 'Factors influencing the severity of rockburst damage in South African gold mines', Journal of the South African Institute of Mining and Metallurgy, vol. 98, pp. 53-57.

Hedley, DGF 1992, Rockburst Handbook for Ontario Hardrock Mines, Special Report SP92-1E, CANMET, pp. 1-305.

Hendron, AJ 1977, Engineering of Rock Blasting on Civil Projects, Prentice Hall, Englewood Cliffs.

Hendron, AJ \& Fernandez G 1983, 'Dynamic and static design considerations for underground chambers', Seismic Design of Embankments and Caverns, American Society of Civil Engineers, Reston, pp. 157-197.

Itasca 2015, Universal Distinct Element Code (UDEC v6.0) User Manual, Itasca Consulting Group, Minnesota.

Kaiser, PK \& Maloney, M 1997, 'Scaling laws for the design of rock support', Pure and Applied Geophysics, vol. 150, pp. 415-434.

Kaiser, PK, Tannant, DD \& McCreath, DR 1996, Canadian Rockburst Support Handbook, Geomechanics Research Centre, Laurentian University, Sudbury.

Labreche, DA 1983, 'Damage mechanisms in tunnels subjected to explosive loads', Proceedings of Seismic Design of Embankments and Caverns, American Society of Civil Engineers, Reston, pp. 128-140.

Langefors, U \& Kihlstrom, B 1963, Rock Blasting, John Wiley and Sons, New York.

Lanzano G, Bilotta, E \& Russo, G 2008, 'Tunnels under seismic loading: a review of damage case histories and protection methods', in G Fabbrocino \& F Santucci de Magistris (eds), Strategy for Reduction of the Seismic Risk, Arti Grafiche La Regione srl, Ripalimosani, pp. 65-74.

McGarr, A 1983, 'Estimating ground motions for small nearby earthquakes, Proceedings of Seismic Design of Embankments and Caverns, American Society of Civil Engineers, Reston, pp. 113-126.

McGarr, A, Green, RWE \& Spottiswoode, SM 1981, 'Strong ground motion of mine tremors: Some implications for near-source ground motion parameters', Bulletin of the Seismological Society of America, vol. 71, pp. 295-319.

Milev, AM \& Spottiswoode, SM 2005, 'Strong ground motion and site response in deep South African mines', Journal of the South African Institute of Mining and Metallurgy, vol. 105, pp. 515-524.

Milev, AM, Spottiswoode, SM \& Stewart, RD 1999, 'Dynamic response of the rock surrounding deep level mining excavations', Proceedings of the 9th Symposium of the International Society for Rock Mechanics, pp. 1109-1114.

Milev, AM, Spottiswoode, SM, Rorke, AJ \& Finnie, GJ 2001, 'Seismic monitoring of a simulated rockburst on a wall of an underground tunnel', Journal of the South African Institute of Mining and Metallurgy, vol. 101, pp. 253-260.

Morissette, P, Hadjigeorgiou, J \& Thibodeau, D 2012, 'Validating a support performance database based on passive monitoring data', in Y Potvin (ed.), Proceedings of the Sixth International Seminar on Deep and High Stress Mining, Australian Centre for Geomechanics, Perth, pp. 27-40.

Pariseau, WG 2011, Design Analysis in Rock Mechanics, Taylor and Francis, London.

Perret, WR 1972, 'Seismic source energies of underground nuclear explosions', Bulletin of the Seismological Society of America, vol. 62, pp. 763-774.

Phillips, JS \& Luke, BA 1990, Tunnel Damage Resulting from Seismic Loading, SAND90-1721C, Sandia National Laboratories, Albuquerque, pp. 1-27.

Potvin, Y 2009, 'Strategies and tactics to control seismic risks in mines', Journal of the Southern African Institute of Mining and Metallurgy, vol. 109, pp. 177-186.

Potvin, Y \& Wesseloo, J 2013, 'Towards an understanding of dynamic demand on ground support', Journal of the Southern African Institute of Mining and Metallurgy, vol. 113, pp. 913-922.

Raffaldi, MJ \& Loken, MC 2016a, 'Rock mass modeling approach for simulating wave propagation, rock fracture, and rock ejection', Proceedings of the 50th US Rock Mechanics Symposium, American Rock Mechanics Association, Alexandria, pp. 12.

Raffaldi, MJ \& Loken, MC 2016b, 'Framework for simulating fracture, ejection, and restraint of rock around a mine drift subjected to seismic loading', Proceedings of the 50th US Rock Mechanics Symposium, American Rock Mechanics Association, Alexandria, pp. 17.

Sharma, S \& Judd, WR 1991, 'Underground opening damage from earthquakes,' Engineering Geology, vol. 30, pp. 263-276.

Starfield, AM \& Cundall, PA 1988, 'Towards a methodology for rock mechanics modelling', International Journal of Rock Mechanics and Mining Science \& Geomechanics Abstract, vol. 24, pp. 99-106.

Swanson, P, Boltz, MS \& Chambers, D 2016, Seismic Monitoring Strategies for Deep Longwall Coal Mines, National Institute for Occupational Safety and Health Report on Investigations, RI 9700, pp. 100.

Wagner, H 1984, 'Support requirements for rockburst conditions,' Proceedings of the 1st International Symposium on Rockburst and Seismicity in Mines, South African Institute of Mining and Metallurgy, Johannesburg, pp. 209-218. 